\title{
Upf1 potentially serves as a RING-related E3 ubiquitin ligase via its association with Upf3 in yeast
}

\author{
SHINYA TAKAHASHI, ${ }^{1,2}$ YASUHIRO ARAKI, ${ }^{1,3}$ YURIKO OHYA, TAKESHI SAKUNO, ${ }^{4}$ SHIN-ICHI HOSHINO, ${ }^{5}$ \\ KENJI KONTANI, HIROSHI NISHINA, ${ }^{2}$ and TOSHIAKI KATADA \\ Department of Physiological Chemistry, Graduate School of Pharmaceutical Sciences, University of Tokyo, Tokyo 113-0033, Japan
}

\begin{abstract}
Three Upf proteins are essential to the nonsense-mediated mRNA decay (NMD) pathway. Although these proteins assemble on polysomes for recognition of aberrant mRNAs containing premature termination codons, the significance of this assembly remains to be elucidated. The Cys- and His-rich repeated $\mathrm{N}$ terminus ( $\mathrm{CH}$ domain) of Upf1 has been implicated in its binding to Upf2. Here, we show that $\mathrm{CH}$ domain also plays a RING-related role for Upf1 to exhibit E3 ubiquitin ligase activity in yeast. Despite the sequence divergence from typical E3-RING fingers, the $\mathrm{CH}$ domain of yeast Upf1 specifically and directly interacted with the yeast E2 Ubc3. Interestingly, Upf1 served as a substrate for the in vitro self-ubiquitination, and the modification required its association with Upf3 rather than Upf2. Substitution of the coordinated Cys and His residues in the $\mathrm{CH}$ domain impaired not only self-ubiquitination of Upf1 but also rapid decay of aberrant mRNAs. These results suggest that Upf1 may serve as an E3 ubiquitin ligase upon its association with Upf3 and play an important role in signaling to the NMD pathway.
\end{abstract}

Keywords: E3; nonsense-mediated mRNA decay (NMD); Upf1; Upf3; ubiquitin ligase

\section{INTRODUCTION}

Eukaryotic cells have evolved mechanisms to ensure precise expression of genetic information, especially in the mRNA decay step by degrading aberrant transcripts. One wellstudied example is nonsense-mediated mRNA decay, referred to as NMD. NMD is an RNA surveillance system that detects and decays rapidly aberrant mRNAs containing premature termination codons (PTCs) to prevent translation of truncated proteins, and it has been observed to function in all eukaryotic cells. Three protein factors termed Upf1-3 are essential for NMD in budding yeast (Leeds et al. 1991; Cui et al. 1995; He and Jacobson 1995;

\footnotetext{
${ }^{1}$ These authors contributed equally to this work.

Present addresses: ${ }^{2}$ Department of Developmental and Regenerative Biology, Medical Research Institute, Tokyo Medical and Dental University, 1-5-45 Yushima, Bunkyo-ku, Tokyo 113-8510, Japan; ${ }^{3}$ Zentrum fur Molekulare Biologie der Universitat Heidelberg (ZMBH), Im Neuenheimer Feld 282, 69120 Heidelberg, Germany; ${ }^{4}$ Laboratory of Chromosome Dynamics, Institute of Molecular and Cellular Biosciences, University of Tokyo, Yayoi Bunkyo-ku, Tokyo 113-0032, Japan; ${ }^{5}$ Department of Biological Chemistry, Graduate School of Pharmaceutical Sciences, Nagoya City University, 3-1 Tanabe-dori, Nagoya 467-8603, Japan.

Reprint requests to: Toshiaki Katada, Department of Physiological Chemistry, Graduate School of Pharmaceutical Sciences, University of Tokyo, Tokyo 113-0033, Japan; e-mail: katada@mol.f.u-tokyo.ac.jp; fax: 81-3-5841-4751.

Article published online ahead of print. Article and publication date are at http://www.rnajournal.org/cgi/doi/10.1261/rna.536308.
}

Lee and Culbertson 1995). Messenger RNAs containing PTCs are selectively stabilized in the mutants of UPF1, $U P F 2$, or UPF3 genes, without affecting the decay rate of most normal mRNAs. These genes have also been conserved in eukaryotes, including yeasts, Caenorhabditis elegans, and mammals, indicating that the roles of Upf proteins are consistent (Pulak and Anderson 1993; Perlick et al. 1996; Lykke-Andersen et al. 2000; Mendell et al. 2000; Serin et al. 2001). Upf1 is an ATP-dependent RNA helicase, localized in the cytoplasm, and mutations affecting its ATPase activity also impair NMD (Czaplinski et al. 1995; Weng et al. 1996a). Upf2, rich in acidic amino acid residues, has an eIF4G-like domain in the middle region. Upf2 localizes in the cytoplasm and interacts with both Upf1 and Upf3 (He et al. 1997). Upf3, rich in basic residues, is a small protein containing nuclear import and export signals and localized in the nucleus (Shirley et al. 1998). There might be at least two surveillance steps, analogized by the mutual requirement of Upf proteins onto polysomes: (1) Upf1 is docked to polysomes, independent of Upf2 or Upf3; and (2) Upf3 is associated with polysomes, dependent on Upf2 (Atkin et al. 1997). Single or multiple deletions of UPF genes exhibit equivalent stabilization of the nonsense mRNAs, indicating that the Upf proteins function as a complex and constitute the core machinery of NMD. 
One model for recognition of a termination codon as a premature transcript is a cis-acting downstream element (DSE), which is located in the $3^{\prime}$ of PTCs (Peltz et al. 1993; Zhang et al. 1995). The RNA-binding protein Hrp1 has been demonstrated to interact with the PGK1 DSE to provide a mark for PTC (Gonzalez et al. 2000). Hrp1 interacts directly with Upf1, suggesting a direct linkage between Upf1 and a signal of PTC. An alternative model for the PTC recognition is the "faux UTR" model, which posits that translation termination at a PTC is intrinsically aberrant because it occurs upstream of elements unable to function as an authentic 3'-UTR (Maderazo et al. 2003; Amrani et al. 2004, 2006; Gaba et al. 2005). Upf1 also interacts with many other proteins for the degradation of aberrant mRNAs and the execution of translation termination. Yeast Upf1 interacts with Upf2, Upf3, and Hrp1. In addition, Upf1 interacts with two polypeptide release factors, eRF1 and eRF3, while Upf2 and Upf3 interact with eRF3 (Wang et al. 2001). Thus, Upf deletion enhances nonsense suppression, suggesting that yeast Upf proteins function not only in NMD but also in the translation termination process (Czaplinski et al. 1998; Maderazo et al. 2000; Wang et al. 2001). NMD most likely takes place in cytoplasmic foci referred to as "processing bodies" ( $\mathrm{P}$ bodies) as Upf1 recruits premature mRNAs to P-bodies and many of the proteins that are involved in decapping and decay enzymes nucleate in P-bodies (Sheth and Parker 2003; Sheth and Parker 2006; Parker and Sheth 2007). However, the regulation of biochemical activities of Upf proteins and the precise mechanisms for their interaction in NMD remain mostly unknown.

Ubiquitin, consisting of 76 amino acids, is highly conserved among all eukaryotes and fulfills important cell functions. The first function identified for ubiquitination is a navigation mark leading to the proteolysis by a multisubunit ATP-dependent protease. Recent works clarify that protein degradation is not the only fate for ubiquitinated proteins. Ubiquitination also regulates certain processes probably through conformational change, rather than proteolysis. These processes include ribosomal function, DNA repair, inflammatory response, and transcription regulation (for review, see Weissman 2001; Fang and Weissman 2004). Ubiquitination contains a cascade of three enzymatic steps. First, free ubiquitin is bound through a thiol linkage to a ubiquitin-activating enzyme (E1): This step requires the hydrolysis of ATP. Second, the ubiquitin is transferred to a conjugating enzyme (E2) using another thiol linkage. Third, a ubiquitin ligase (E3) transferred the activated ubiquitin from the E2 to target proteins. The specificity for the ubiquitination of target protein is governed by specific recognition of the substrate protein and the E2 through one of hundreds of E3s. E3s utilize one of the catalytic domains, a RING-finger domain ( $\sim 70$ amino acid residues), or an HECT domain ( $\sim 350$ residues) for the association with E2. The RING-finger domain features eight Cys or His residues that ligand two zinc ions in a cross-braced fashion. Several other RING-related domains, such as the PHD finger and the FYVE finger, have also been implicated in ubiquitination (for review, see Fang et al. 2003). In addition, the U-box domain consisting of hydrogen bonds and a saltbridge-mediated motif is predicted to be a structure similar to the RING finger (Hatakeyama et al. 2001).

In this report, we show that the N-terminal Cys- and His-rich repeats of yeast Upf1, which has been previously characterized as a Upf2-binding region, constitute an E3 RING-related domain for the yeast E2 Ubc3 and that Upf1 is capable of serving as a substrate for the self-ubiquitination upon its association with Upf3. The present findings suggest that Upf1 has the intrinsic activity of E3 ubiquitin ligase, and ubiquitin modification mediated through Upf1 may be involved in the signaling pathway from the recognition of PTC to NMD.

\section{RESULTS AND DISCUSSION}

\section{Upf1 has a RING-related domain that is characterized in E3 ubiquitin ligases}

Upfl possesses nucleic acid-dependent ATPase and helicase activities in vitro (Czaplinski et al. 1995; Weng et al. 1996a). This has also been confirmed by the evidence that an ATPase/helicase domain is well conserved in the middle regions of various species of Upf1. In addition, Upf1 has a Cys- and His-rich $(\mathrm{CH})$ domain or a putative $\mathrm{Zn}$-finger motif in its $\mathrm{N}$-terminal region, and this domain appears to serve as an interaction site for $\mathrm{Upf} 2$ in a yeast two-hybrid assay (He et al. 1997). Interestingly, Kadlec et al. (2006) have recently reported that the N-terminal $\mathrm{CH}$ domain of Upf1 contains structural modules similar to the RING-box or U-box found most often in E3 ubiquitin ligases, although these modules could not be identified by sequence analysis. As shown in Figure 1, the $\mathrm{CH}$ domain was also conserved from yeast to human. Sequence alignments of the $\mathrm{CH}$ domain indicated that the cluster of Cys and His is completely conserved, in contrast to the other amino acid residues. Especially, four $\mathrm{C} / \mathrm{H}-\mathrm{X}-\mathrm{X}-(\mathrm{X})-\mathrm{C} / \mathrm{H}$ repeats (Fig. 1, ScUpf1, 62-65,94-98,122-125,148-152) within the $\mathrm{CH}$ domain allowed us to confirm the presence of a RINGrelated domain in various species of Upfl. We therefore evaluated whether budding yeast Upf1 is capable of serving as an E3 ubiquitin ligase by analyzing its interaction with the yeast E2 and the occurrence of its self-ubiquitination.

\section{Budding yeast Upf1 interacts specifically with yeast E2 Ubc3 through the $\mathrm{CH}$ domain}

If budding yeast Upf1 serves as a RING-related E3 ubiquitin ligase via its $\mathrm{CH}$ domain, it should interact with yeast E2 proteins. There are at least 13 known members (Ubc1-13) of E2 in S. cerevisiae. To identify the yeast E2 


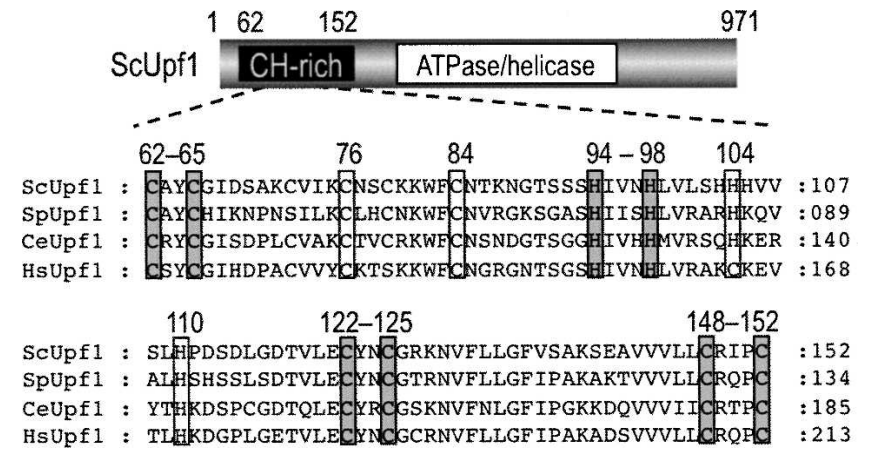

FIGURE 1. Sequence alignments of the $\mathrm{N}$-terminal $\mathrm{CH}$-rich domain of Upf1 protein in various species. The alignment of the $\mathrm{CH}$ domain was performed with Clustal W. (Gray or white box) The most conserved cysteine and histidine residues. (Sc) Saccharomyces cerevisiae; (Sp) Schizosaccharomyces pombe; (Ce) Caenorhabditis elegans; (Hs) Homo sapiens.

specific for Upf1, we purified all the yeast E2 members as glutathione-S-transferase (GST)-fused proteins from Escherichia coli. The 13 purified E2 proteins were incubated with lysates from upfis cells producing Flag-Upf1 by means of galactose-inducible single-copy vector and subjected to a pull-down assay with glutathione-Sepharose resin. Proteins retained on each of the E2-bound resins were separated by SDS-PAGE and immunoblotted with an anti-Flag antibody. As shown in Figure 2A, Flag-Upf1 could be observed in the fractions of Ubc3 and Ubc9.

Since Upf1, Upf2, and Upf3 often exist as a complex in the NMD pathway, we investigated whether the other Upf proteins are required for the interaction of Upf1 with Ubc3 or Ubc9. For the analysis, the purified E2 proteins were also incubated with lysates from upf1 $u p f 2 \Delta$ or upf1s upf $3 \Delta$ cells expressing Flag-Upf1 and subjected to the GST pulldown assay. As shown in Figure 2B, the interaction between Upf1 and Ubc3 or Ubc9 was still observed upon the disruption of UPF2 or UPF3 gene, indicating that neither Upf2 nor Upf3 is required for their interaction. We further investigated their interaction with the purified recombinant proteins. As shown in Figure 2C, Upf1 was capable of directly associating with the purified GST-Ubc3 (Fig. 2C, lane 1) or GST-Ubc9 (Fig. 2C, lane 3), but not with GST alone (Fig. 2C, lane 5).

E3 ubiquitin ligases have been reported to associate with E2 through either the RING or HECT domain of E3. To confirm the role of the RING-related CH domain in Upf1, only the domain fragment (62-152) was purified as a GSTfused protein and subjected to the GST pull-down assay. As shown in Figure 2D, the interaction of the $\mathrm{CH}$ domain with Ubc3 was clearly observed (Fig. 2D, lane 1). In contrast, the $\mathrm{CH}$ domain alone failed to interact with Ubc9 (Fig. 2D, lane 2), suggesting that Upf1 may require a region(s) other than the $\mathrm{CH}$ domain for the interaction with Ubc9. This idea was supported by the finding that a Upf1 mutant lacking the $\mathrm{CH}$ domain was still capable of binding to Ubc9
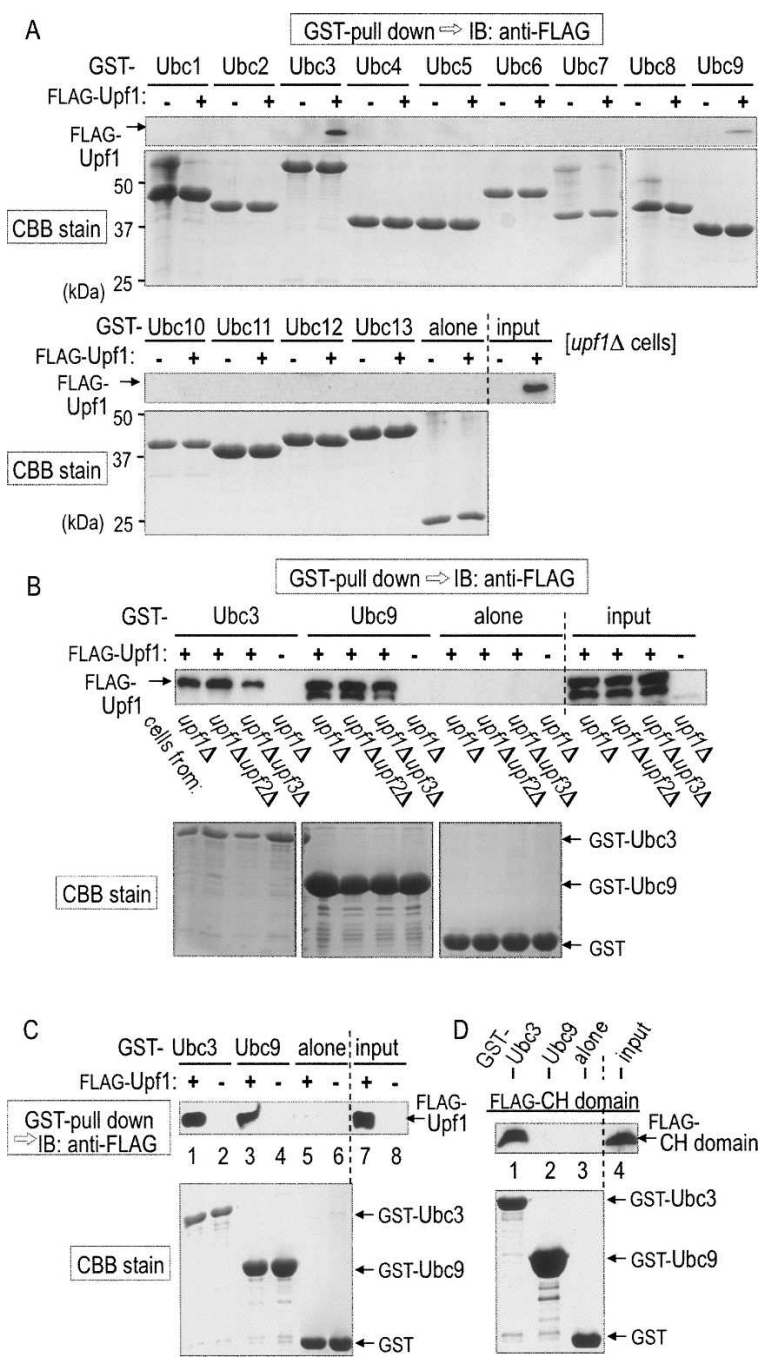

FIGURE 2. Budding yeast Upf1 directly interacts with the yeast E2 Ubc3 through the RING-related $\mathrm{CH}$ domain. (A) Yeast E2 proteins (Ubc1-13) fused with GST were purified from E. coli and mixed with extracts from $u p f 1 \Delta$ cells producing Flag-tagged Upf1 $(+)$ or Flag alone (-) under the control of GAL1 promoter. (Top panel) The purified GST-Ubc proteins were pulled down with glutathioneSepharose resin, and proteins retained on the resin were separated by SDS-PAGE and immunoblotted with an anti-Flag antibody. (Bottom panel) The GST-Ubc proteins retained on the resin were also stained with Coomassie brilliant blue (CBB) after SDS-PAGE. ( $B$, top panel) The purified GST-Ubc3, GST-Ubc9, or GST alone was mixed with cell extracts that had been prepared from upfls, upfis $u p f 2 \Delta$ or $u p f 1 \Delta u p f 3 \Delta$ variant cells producing Flag-tagged Upf1 (+) or Flag alone (-) and subjected to the pull-down assay for the detection of Flag-Upf1. (C) Flag-Upf1 was affinity-purified with the anti-Flag antibody from $u p f 1 \Delta$ cells. (Top panel) The Flag-Upf1 was mixed with the purified GST-Ubc3, GST-Ubc9, or GST alone and subjected to the pull-down assay for the detection of Flag-Upf1. ( $D$, top panel) Flag$\mathrm{CH}$ domain (the amino acid sequence of 62-152) that had been affinity-purified with the anti-Flag antibody from upf $1 \Delta$ cells was mixed with the purified GST-Ubc3, GST-Ubc9, or GST alone and subjected to the pull-down assay for the detection of the Flag- $\mathrm{CH}$ domain. ( $A-D$, bottom panels) CBB stain of the GST-fused proteins. 
(data not shown). We thus concluded that the RINGrelated $\mathrm{CH}$ domain is responsible for the direct interaction of Upf1 with Ubc3 and that neither Upf2 nor Upf3 is required for the direct interaction. In the following in vitro study, we used Ubc3 as the yeast E2 for Upf1.

\section{Up1f serves as a substrate for self-ubiquitination dependent on its RING-related $\mathrm{CH}$ domain}

To obtain the direct evidence that Upf1 exhibits E3 activity via its RING-related $\mathrm{CH}$ domain, we performed an in vitro self-ubiquitination assay. As shown in Figure 3A, we purified full-length Upf1 (wild type [WT]) and a variant $(\Delta \mathrm{CH})$ lacking the $\mathrm{CH}$ domain $(62-152)$ as Flag-fused proteins from upf1 $\Delta$ cells (Fig. 3A, lanes 2,3) and performed the self-ubiquitination assay in a reaction mixture consisting of a mouse recombinant E1, the purified GSTUbc3, ubiquitin, and ATP. The reaction mixtures were separated by SDS-PAGE and immunoblotted with anti-
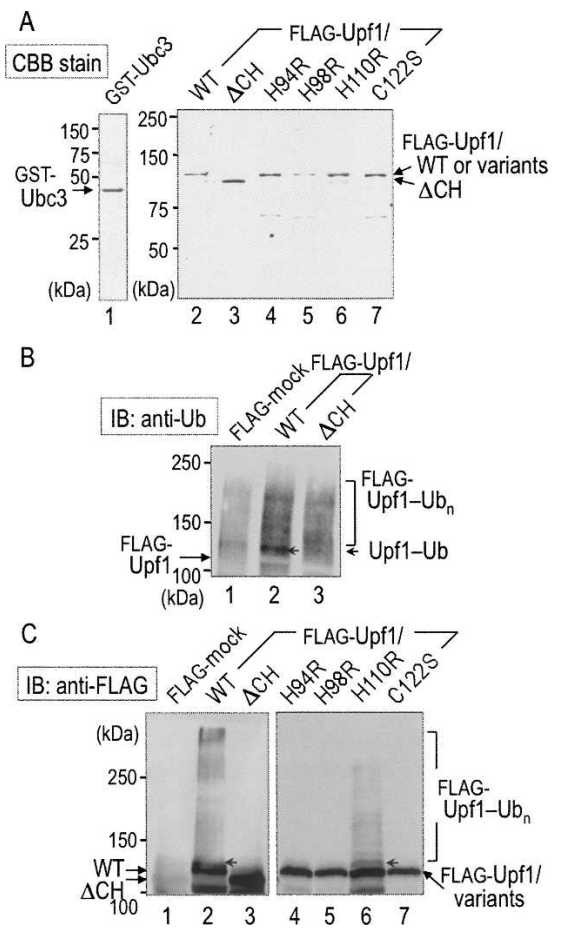

FIGURE 3. Self-ubiquitination of Upf1 requires the RING-related $\mathrm{CH}$ domain. (A) Wild-type (WT) and variants of Upf1 were affinitypurified from $u p f 1 \Delta$ cells producing the indicated forms of Flag-Upf1 under the control of the GAL1 promoter. (Lanes 2-7) The purified Flag-Upf1 proteins, together with (lane 1) GST-Ubc3, were stained with CBB after SDS-PAGE. (B) The indicated Flag-Upf1 proteins were subjected to the in vitro ubiquitination assay in the presence of a mouse recombinant E1, E2 (GST-Ubc3), ubiquitin, and ATP. The reaction mixture was separated by SDS-PAGE and immunoblotted with an anti-ubiquitin (Ub) antibody. (C, right panel) The reaction mixture was also subjected to immunoblot assay with the anti-Flag antibody. (Arrowhead) A possible position of mono-ubiquitinated Flag-Upf1 (Upf1-Ub). High-molecular-weight smear bands represent the poly-ubiquitinated form of Flag-Upf1 $\left(\mathrm{Upfl}-\mathrm{Ub}_{\mathrm{n}}\right)$. ubiquitin and anti-Flag antibodies for detection of the Upf1 modification. As shown in Figure 3B, the anti-ubiquitin immunoblot indicated a specific ubiquitin-positive band, suggestive of the mono-ubiquitination, in the Flag-Upf1/ WT fraction (Fig. 3B, lane 2, arrowhead): The positive band migrated more slowly than a position of the unmodified Flag-Upf1. The anti-Flag immunoblot (Fig. 3C) clearly showed that, in addition to the mono-ubiquitination, high-molecular-weight smear bands, indicative of the polyubiquitinated Upf1, were detected in WT (Fig. 3C, lane 2), but not in $\triangle \mathrm{CH}$ (Fig. 3C, lane 3). These results suggest that Upf1 serves as a substrate for self-ubiquitination in vitro and that the $\mathrm{CH}$ domain is required for the ubiquitin ligase activity of Upfl.

To investigate the importance of the RING-related $\mathrm{CH}$ domain, a single point mutation was introduced into a Cys or a His residue within the domain. As described above (see Fig. 1), we speculated that C62-C65, H94-H98, C122C125, and C148-C152 are possible candidates of the cluster of RING-related motif in Upf1, while H110 is located outside this cluster. Thus, several Cys residues and His 110 were replaced by Arg and Ser, respectively, and the Upf1 variants were also purified as Flag-fused proteins (Fig. 3A, lanes 4-7). As shown in Figure 3C, high molecular polyubiquitinated forms observed with Upf1/WT were almost entirely eliminated if a Upf1/H94R (Fig. 3C, lane 4), H98R (Fig. 3C, lane 5), or C122S (Fig. 3C, lane 7) variant was used. In contrast, the Upf1/H110R variant (Fig. 3C, lane 6) appeared to serve as a substrate for poly-ubiquitination like Upf1/WT. These results are fully consistent with the previous findings that RING-related E3 ligase activity is dependent on zinc-coordinated Cys and His residues.

\section{RING-related $\mathrm{CH}$ domain of Upf1 is responsible for signaling to NMD pathway}

As described previously, mRNAs containing PTCs are rapidly degraded through the NMD pathway, and deletion of the UPF1 gene exhibits the stabilization of nonsense mRNAs (Leeds et al. 1991). We thus investigated whether the Upf1 variants lacking E3 ligase activity are capable of activating the NMD pathway. For the analysis, we monitored the degradation rates of nonsense and normal mRNAs using $P G K 1_{N 103} p G$ and $P G K 1 p G$, respectively, in $u p f 1 \Delta$ cells. The expression level of each Upf1 variant was unchanged at least for the observation periods (data not shown). As shown in Figure 4A, degradation of the nonsense mRNA in upfl $1 \Delta$ cells (Fig. 4A, first panel), which has been characterized as its slow-decay phenotype, was effectively accelerated by the introduction of Upf1/WT (Fig. 4A, second panel). However, the introduction of Upf1/ $\Delta \mathrm{CH}$ (Fig. 4A, third panel), H94R (Fig. 4A, fourth panel), H98R (Fig. 4A, fifth panel), or C122S (Fig. 4A, seventh panel), which did not serve as a substrate of the self-ubiquitination (see Fig. 3C), failed to stimulate the nonsense mRNA decay. 


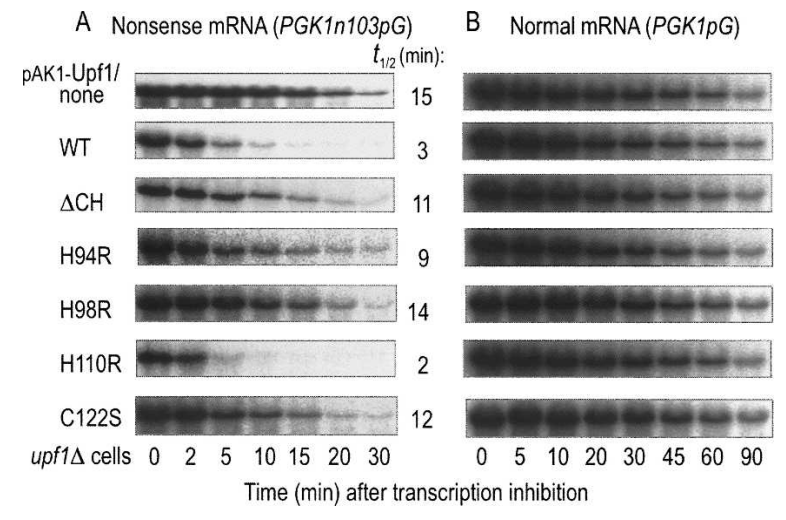

FIGURE 4. Upf1-stimulated degradation of aberrant mRNAs is impaired by mutations in its RING-related $\mathrm{CH}$ domain. The upfls cells producing $(A) \mathrm{PGK}_{\mathrm{N} 103} \mathrm{pG}$ and $(B)$ PGK1pG reporters were transformed with plasmids carrying WT or the indicated $\mathrm{CH}$-domain variants $(\Delta \mathrm{CH}, \mathrm{H} 94 \mathrm{R}, \mathrm{H} 98 \mathrm{R}, \mathrm{H} 110 \mathrm{R}, \mathrm{C} 122 \mathrm{~S})$ of Upf1. The transformants were grown in a galactose-containing medium and harvested at mid-log phase. Transcription was repressed by the addition of glucose, and the cells were further incubated for the indicated times. The signals were quantified using a PhosphorImager and corrected for a loading control using the SRP RNA scR1. The half-lives of $\mathrm{PGK} 1_{\mathrm{N} 103} \mathrm{pG}$ reporter were obtained from three independent experiments, and the mean values ( $\mathrm{min})$ are shown at the right.

As expected, the Upf1/H110R variant that retains E3 ligase activity exhibited the stimulatory effect (Fig. 4A, sixth panel) as Upf1/WT. On the contrary, the decay rate of the normal mRNA was not altered by the introduction of any of the Upf1/WT or variants (Fig. 4B). These results suggested that $\mathrm{CH}$ domain characterized as an E3-RING module by the present study is responsible for the Upf1mediated signaling to the NMD pathway.

\section{E3 ubiquitin ligase activity of RING-related Upf1 requires its interaction with Upf3}

Although the RING-related $\mathrm{CH}$ domain of Upf1 directly interacted with the yeast E2 Ubc3 in a manner independent of Upf2 or Upf3 (see Fig. 2), this domain has been previously identified as an important region for the binding to Upf2. Therefore, we further investigated the relationship between the $\mathrm{CH}$-dependent ubiquitin ligase and the complex formation among Upf proteins. For the analysis, we first constructed upfis cells, in which the chromosomal copy of UPF2 was tagged with 9Myc, and various forms of Flag-Upf1 were also produced by means of the control with single-copy vectors. The various forms of Flag-Upf1 in the cell lysates were immunoprecipitated with the anti-Flag antibody and analyzed for their interaction with Upf2-Myc. As shown in Figure 5A, not only Upf1/WT (Fig. 5A, lane 2) but also all the variants (Fig. 5A, lanes 3-7) were capable of immunoprecipitating Upf2, although immunoprecipitated amounts of Upf2 were slightly lower in Upf1/ $\mathrm{CH}, \mathrm{H} 94 \mathrm{R}$, $\mathrm{H} 98 \mathrm{R}$, and C122S variants than in Upf1p/WT or H110R variants.
We next investigated the interaction between Upf1 and Upf3 using the same strategy in the cell construction; the results are shown in Figure 5B. Quite interestingly, Upf1/ WT (Fig. 5B, lane 2) and Upf1/H110R variants (Fig. 5B, lane 6) did precipitate Upf3, but Upf1/ $\mathrm{CH}$ (Fig. 5B, lane 3 ) or other variants (Fig. 5B, lanes $4,5,7$ ) did not. Since
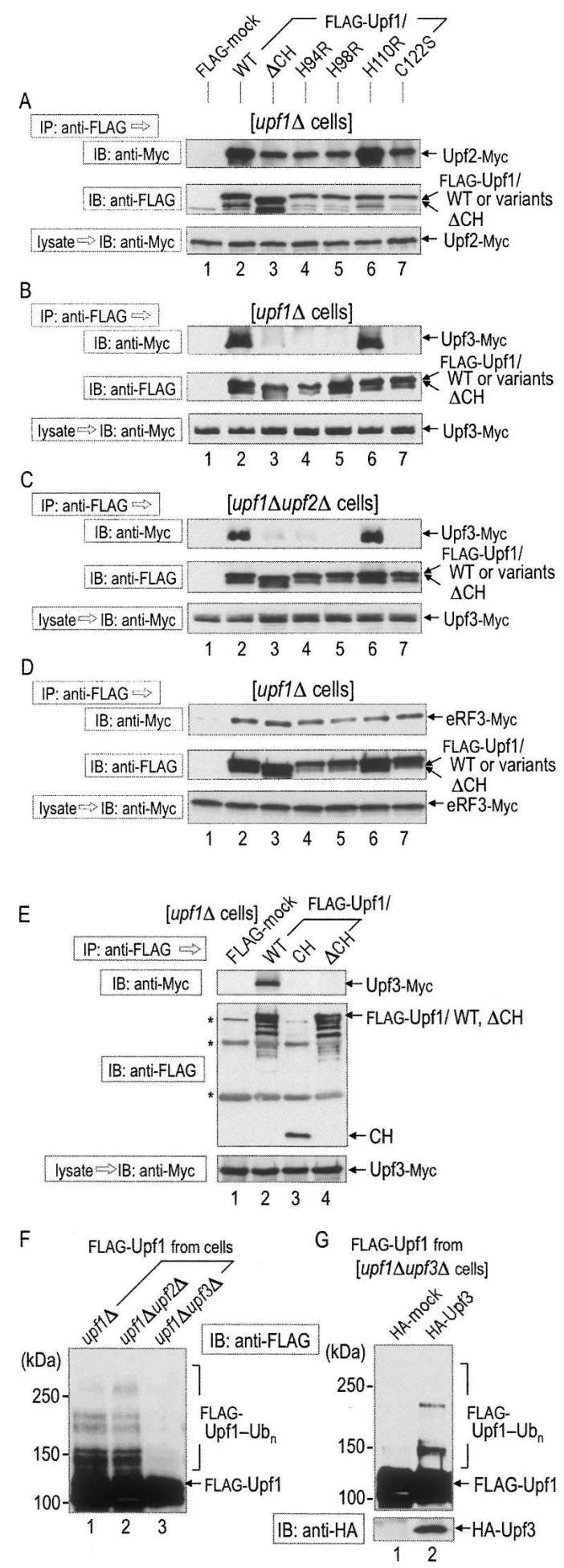

FIGURE 5. (Legend on next page) 
Upf2 interacts with both Upf1 and Upf3 through different regions (He et al. 1996, 1997), Upf2 might mediate the immunoprecipitation between Upf1 and Upf3. To clarify this possibility, we investigated the effect of UPF2 deletion using $u p f 1 \Delta u p f 2 \Delta$ cells. As shown in Figure 5C, deletion of the UPF2 gene did not reduce the interaction of Upf3 with Upf1/WT (Fig. 5C, lane 2) and Upf1/H110R variants (Fig. 5C, lane 6). The RING-related $\mathrm{CH}$ domain directly interacted with the yeast E2 Ubc3 (see Fig. 2). Therefore, we further investigated the direct role of the $\mathrm{CH}$ domain in the interaction with Upf3. As shown in Figure 5E, the Flag- $\mathrm{CH}$ domain failed to interact with Upf3 (Fig. 5E, lane 3), suggesting that the $\mathrm{CH}$ domain alone is not sufficient for the interaction. These results indicate that Upf1 is capable of interacting with Upf3 independent of Upf2 and that the RING-related $\mathrm{CH}$ domain is necessary but not sufficient for their interaction.

We further investigated the interaction between Upf1 and eRF3 in upf1s cells, since Upf1 interacts with the release factors, eRF1 and eRF3, to regulate the translation termination efficiency (Czaplinski et al. 1998; Kobayashi et al. 2004). As shown in Figure 5D, the interaction between Upf1 and eRF3 was not affected by the deletion of the $\mathrm{CH}$ domain or its mutations (Fig. 5D, lanes 2-7), indicating that the $\mathrm{CH}$ domain is not involved in the interaction between Upf1 and eRF3. Thus, disruption of the RINGrelated $\mathrm{CH}$ domain appears to abolish specifically the interaction between Upf1 and Upf3 without marked alteration in the Upf1-Upf2 or Upf1-eRF3 assembly.

We finally investigated whether other Upf proteins are required for the intrinsic activity of Upf1 as an E3 ubiquitin ligase in vitro. For the analysis, Upf1 was

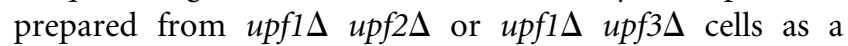
Flag-tagged form and subjected to the in vitro selfubiquitination assay. As shown in Figure 5F, Upf1 obtained

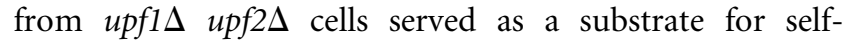

FIGURE 5. Interaction between RING-related $\mathrm{CH}$ domain and Upf3 is required for self-ubiquitination of Upf1. (A) Lysates were prepared from $u p f 1 \Delta$ cells producing Upf2-Myc and various forms of Flag-Upf1 as shown in Figure 3. (B) Lysates were prepared from upfis cells producing Upf3-Myc and various forms of Flag-Upf1. (C) Lysates were prepared from upf1s upf2s double-mutant cells producing Upf3-Myc and various forms of Flag-Upf1. (D) Lysates were prepared from $u p f 1 \Delta$ cells producing eRF3-Myc and various forms of FlagUpf1. (E) Lysates were prepared from $u p f 1 \Delta$ cells producing Upf3Myc and various forms of Flag-Upf1. (Asterisks) Nonspecific bands. These lysates were immunoprecipitated with the anti-Flag antibody to detect the associated $(A) \mathrm{Upf} 2-\mathrm{Myc}$, and $(B, C, E)$ Upf3-Myc eRF3-Myc (for $D$ ). (F) Lysates from upf $1 \Delta, u p f 1 \Delta u p f 2 \Delta$, and upf1 $1 \Delta$ upf $3 \Delta$ cells producing Flag-Upf1 were immunoprecipitated with the anti-Flag antibody. The precipitated fractions containing Flag-Upf1 were subjected to the in vitro ubiquitination assay as described in Figure 3. (G) Lysates from $u p f 1 \Delta u p f 3 \Delta$ cells producing Flag-Upf1 and HAmock or HA-Upf3 were immunoprecipitated with the anti-Flag antibody. The precipitated fractions containing Flag-Upfl were subjected to the in vitro ubiquitination assay. ubiquitination (Fig. 5F, lane 2), but that from upf1 upf3s cells did not (Fig. 5F, lane 3). To confirm the requirement of Upf3 for ubiquitin ligase activity, we examined the rescuable effect of Upf3 in upf $1 \Delta$ upf $3 \Delta$ cells. As shown in Figure 5G, Upf1 obtained from the Upf3-rescued upf1 upf $3 \Delta$ cells served as a substrate for self-ubiquitination. These results indicate that Upf3 is required for the E3 ubiquitin ligase activity of Upf1.

\section{Possible roles of E3 ubiquitin ligase activity of Upf1 in signaling of NMD pathway}

In the present study, we have identified that Upf1 has intrinsic activity of RING-related E3 ubiquitin ligase in terms of self-ubiquitination and that the enzymic activity requires its association with Upf3 probably through a region(s) other than the $\mathrm{CH}$ domain: The $\mathrm{CH}$ domain alone is not sufficient for the interaction. Furthermore, the RING-related enzymic activity appears to have a correlation with the Upf1-dependent activation of the NMD pathway. At present, we cannot totally rule out the possibility that RING mutations disrupt conformation of Upfl, leading to the inhibition of activities and/or interactions unrelated to the Upf3-dependent ubiquitin ligase activity. However, it is tempting to speculate that ubiquitin modification induced by Upf1 ligase plays an important role(s) in the signal transduction from PTC recognition to the NMD pathway. In this regard, it has been previously reported that the lack of and mutations in the $\mathrm{CH}$ domain of Upf1 suppress leu2-2 and tyr7-1 nonsense alleles, stabilize nonsense-containing mRNAs, inactivate the ability to enhance translation termination at a nonsense codon, reduce RNA binding properties, and destabilize the surveillance complex, especially for the Upf1p-Upf2p interaction (Weng et al. 1996b). It is thus very likely that the E3 ubiquitin ligase activity of Upf1 found in this study may play a direct role in some of these phenotypes.

Although the direct interaction between Upf1 and Upf3 was not clearly observed in a yeast two-hybrid assay using upf2 $\Delta$ cells (He et al. 1997), there are several reports showing that Upf3 is capable of immunoprecipitating Upf1 in a manner independent of Upf2 (Ohnishi et al. 2003; Gehring et al. 2005). In the present study, we also observed that Upf1 has the ability to interact with Upf3 in yeast extracts (Fig. 5B) and that the Upf1-Upf3 interaction is not affected by UPF2 deletion (Fig. 5C). This allows us to speculate that cytoplasmic factors, such as poly-ribosomes or other proteins, may be required for Upf1 binding to Upf3.

Recent studies have suggested the importance of phosphorylation of Upf proteins. In yeast, the phosphorylation of Upf2 is crucial for its interaction with Hrp1 and its ability to elicit NMD (Wang et al. 2006). In mammalian cells, Smg1, an essential factor for the NMD pathway, phosphorylates Upf1 (Denning et al. 2001; Yamashita et al. 2001). 
The phosphorylation of Upf1 by Smg1 requires both Upf2 and Upf $3 \mathrm{~b}$, and the phosphorylated form of Upf1 induces remodeling of the surveillance complex and the triggering of NMD (Ohnishi et al. 2003; Kashima et al. 2006). In the present study, we observed in vitro self-ubiquitination of Upf1, and this modification required its interaction with Upf3. The relations between phosphorylation and ubiquitination are numerous and highly complicated. Indeed, it has been clarified that ubiquitination can regulate phosphorylation both directly and indirectly (for review, see Fang et al. 2003; Fang and Weissman 2004). It would be interesting to clarify whether the ubiquitin ligase activity of Upf1 is stimulated via its phosphorylation and whether these post-translational modifications are conserved among various species like the regulatory mechanism of NMD.

The role of ubiquitin ligase (E3) is transferring the activated ubiquitin from E2 to target proteins. We thus consider that ubiquitination of Upf1 may occur by Upf1 itself only in an in vitro assay, and the ubiquitination for Upf1 is only the indication of E3 activity of Upf1 itself. Upf1 obtained from upf1 $1 \Delta p f 3 \Delta$ cells did not serve as a substrate for the self-ubiquitination (Fig. 5F). Upf3 might act as a key regulator for the E3 ubiquitin ligase, probably through the conformational change of Upfl, although the real substrate(s) for the Upf1-dependent ubiquitination has not been determined in the present study. The direct interaction between Upf1 and Upf3 might play a role in remodeling of the Upf1 itself or the Upf1 complex, and recruit the substrates, which regulate the NMD pathway to the $\mathrm{CH}$ domain.

\section{MATERIALS AND METHODS}

\section{Yeast strains and construction of plasmids and variants}

The wild-type strain used in this study is W303-1A (MATa, ade21, can1-11, his3-11, 15, leu2-3 112, trp1-1, ura3-1). Yeast cells were grown in standard culture media and transformed with DNA by the lithium acetate method. Disruption of UPF genes was achieved using PCR-based methods (Goldstein and McCusker 1999; Araki et al. 2001; Takahashi et al. 2003), and the disruption was confirmed by phenotypic analysis and/or PCR reactions with primers specific for the genes. Plasmids for expressing the fulllength (WT), $\mathrm{CH}$ domain $(\mathrm{CH}), \mathrm{CH}$-deleted $(\Delta \mathrm{CH})$, and pointmutated (H94R, H98R, H110R, and C122S) forms of Upf1 and the full-length Upf3 were constructed as follows: The wild-type $U P F 1$ and UPF3 were amplified from the genomic DNA by PCR. These fragments were inserted into the SalI (for UPF1) or EcoRI/ SalI (for UPF3) sites of the pBluescript II SK- vector. The variants of Upf1 were generated as described previously (Takahashi et al. 2003). DNA fragments of these alleles were subcloned into pTRPGAL1- (or pURAGAL1-) $\mathrm{His}_{6}$-Flag (or $\mathrm{His}_{6}$-HA) to generate pTRPGAL1- (or pURAGAL1-) His $_{6}$-Flag-UPF1 or upf1 variant

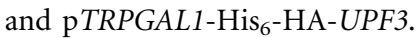

\section{Expression of recombinant proteins}

Glutathione-S-transferase (GST)-fused forms of Ubc1-13 proteins were expressed in E. coli strain BL21-CodonPlus-RIL (Stratagene). The bacterial cells, grown at $37^{\circ} \mathrm{C}$ to an optical density were induced with $1 \mathrm{mM}$ isopropyl- $\beta$ - $d$-thiogalactopyranoside (IPTG) and harvested after $16 \mathrm{~h}$ of culture at $20^{\circ} \mathrm{C}$. The cells were lysed in a sonication buffer $(50 \mathrm{mM}$ Tris- $\mathrm{HCl}$ at $\mathrm{pH} 7.4,100 \mathrm{mM} \mathrm{NaCl}$, $5 \mathrm{mM} \mathrm{MgCl}_{2}$, and $5 \mathrm{mM}$ dithiothreitol) and sonicated. After centrifugation $(30,000 \mathrm{~g}$ for $1 \mathrm{~h})$, the supernatant was mixed with glutathione Sepharose $4 \mathrm{~B}$ and rotated for $2 \mathrm{~h}$ at $4^{\circ} \mathrm{C}$. The beads were washed and eluted with glutathione. The eluted fractions were stored at $-80^{\circ} \mathrm{C}$. Protein concentrations were estimated by comparison of Coomassie brilliant blue (CBB)-stained band intensities with bovine serum albumin as a standard.

\section{Protein preparation, immunoprecipitation, and Western blot analyses}

Logarithmically growing cells were pelleted, washed once, and resuspended in a lysis buffer consisting of $50 \mathrm{mM}$ Tris- $\mathrm{HCl}(\mathrm{pH}$ 7.4), $150 \mathrm{mM} \mathrm{NaCl}, 5 \mathrm{mM}$ EDTA, $1 \mathrm{mM}$ dithiothreitol, $0.1 \% \mathrm{NP}-$ 40 , and protease inhibitors. The cells were mixed with glass beads and disrupted by 12 cycles of vortexing for $30 \mathrm{sec}$ followed by incubating for $1 \mathrm{~min}$ on ice. The cell extracts were obtained by two consecutive runs of centrifugation $(15,000 \mathrm{~g}$ for $10 \mathrm{~min})$. Immunoprecipitation of tagged proteins was performed as follows. After addition of anti-Flag antibody conjugated-beads (M2-AgaroseAFFINITY; Sigma), the extracts were incubated on a rotator for $2 \mathrm{~h}$ at $4^{\circ} \mathrm{C}$. The beads were pelleted and washed extensively with the lysis buffer without protease inhibitors. Proteins retained on the beads were eluted with a ubiquitination reaction buffer containing Flag peptide (for Ub assay) or with an SDS-PAGE sample buffer by boiling for $5 \mathrm{~min}$. The cell extracts and the eluted fractions were subjected to SDS-PAGE and immunoblotted with anti-Myc (9E10; Sigma) and anti-Flag (M2; Sigma) monoclonal antibodies.

\section{In vitro ubiquitination assay}

An in vitro ubiquitination assay was performed as described previously (Albert et al. 2002) with some modifications. In brief, $50 \mathrm{ng}$ of mouse E1 (WAKO), $100 \mathrm{ng}$ of Ubc3 that had been purified on glutathione Sepharose 4B and digested as a GST tagfree form with PreScission protease (Amersham Pharmacia), and $500 \mathrm{ng}$ of Flag-Upf1 were incubated in a $20 \mu \mathrm{L}$ reaction mixture consisting of $3 \mu \mathrm{g}$ of bovine ubiquitin (Sigma), $2 \mathrm{mM}$ ATP, 10 $\mathrm{mM}$ creatine phosphate (Calbiochem), and $10 \mathrm{U}$ of creatine phosphokinase (Sigma) in $50 \mathrm{mM}$ Tris- $\mathrm{HCl}$ (pH 7.5), $50 \mathrm{mM}$ $\mathrm{KCl}, 2.5 \mathrm{mM} \mathrm{MgCl}_{2}, 0.5 \mathrm{mM} \mathrm{Na-EDTA}$ ( $\mathrm{pH} 8.0$ ), and $0.25 \mathrm{mM}$ dithiothreitol for $2 \mathrm{~h}$ at $30^{\circ} \mathrm{C}$. The reaction mixture was subjected to SDS-PAGE and immunoblotted with anti-Ub (P4D1; Santa Cruz) and anti-Flag antibody for detection of Flag-Upf1.

\section{Messenger RNA decay assay}

The pRP602 and pRP611 plasmids encoding the PGK1pG and $\mathrm{PGK} 1_{\mathrm{N} 103} \mathrm{pG}$ reporter mRNAs under control of the GAL1 promoter were transformed in yeast cells. Degradation of these reporters was detected as described previously (Muhlrad et al. 1994, 1995), with some modifications (Takahashi et al. 2003). 
Each strain was incubated at $25^{\circ} \mathrm{C}$, and transcription of the reporters was blocked by wash once and addition of SC-UW medium containing $4 \%$ glucose. The cells were further incubated for the indicated times, pelleted down, and immediately frozen in liquid nitrogen. RNA that had been extracted by the hot-phenol procedure (Boeck et al. 1998) was separated by agarose-gel electrophoresis and transferred to the Hybond XL (Amersham Pharmacia). The reporters were detected by Northern blotting using an oligonucleotide oRP121 (5'-AATTCCCCCCCCCCCCC CCCCCA-3').

All experiments were performed at least three times with different samples of the yeast strains, and the results were fully reproducible. Hence, most of the data shown are representative of several independent experiments.

\section{ACKNOWLEDGMENTS}

We thank Dr. A. Yamashita (Yokohama City University) for personal communication and charitable comments. This work was supported in part by research Grants (to S.T., K.K., and T.K.) from the Ministry of Education, Culture, Sports, Science and Technology (MEXT) of Japan, and the Japan Society for the Promotion of Science (JSPS).

Received March 5, 2008; accepted June 10, 2008.

\section{REFERENCES}

Albert, T.K., Hanzawa, H., Legtenberg, Y.I., de Ruwe, M.J., van den Heuvel, F.A., Collart, M.A., Boelens, R., and Timmers, H.T. 2002. Identification of a ubiquitin-protein ligase subunit within the CCR4-NOT transcription repressor complex. EMBO J. 21: 355364.

Amrani, N., Ganesan, R., Kervestin, S., Mangus, D.A., Ghosh, S., and Jacobson, A. 2004. A faux 3'-UTR promotes aberrant termination and triggers nonsense-mediated mRNA decay. Nature 432: 112-118.

Amrani, N., Sachs, M.S., and Jacobson, A. 2006. Early nonsense: mRNA decay solves a translational problem. Nat. Rev. Mol. Cell Biol. 7: 415-425.

Araki, Y., Takahashi, S., Kobayashi, T., Kajiho, H., Hoshino, S., and Katada, T. 2001. Ski7p G protein interacts with the exosome and the Ski complex for $3^{\prime}$-to- $5^{\prime}$ mRNA decay in yeast. EMBO J. 20: 4684-4693.

Atkin, A.L., Schenkman, L.R., Eastham, M., Dahlseid, J.N., Lelivelt, M.J., and Culbertson, M.R. 1997. Relationship between yeast polyribosomes and Upf proteins required for nonsense mRNA decay. J. Biol. Chem. 272: 22163-22172.

Boeck, R., Lapeyre, B., Brown, C.E., and Sachs, A.B. 1998. Capped mRNA degradation intermediates accumulate in the yeast $s p b 8-2$ mutant. Mol. Cell. Biol. 18: 5062-5072.

Cui, Y., Hagan, K.W., Zhang, S., and Peltz, S.W. 1995. Identification and characterization of genes that are required for the accelerated degradation of mRNAs containing a premature translational termination codon. Genes \& Dev. 9: 423-436.

Czaplinski, K., Weng, Y., Hagan, K.W., and Peltz, S.W. 1995. Purification and characterization of the Upfl protein: A factor involved in translation and mRNA degradation. RNA 1: 610-623.

Czaplinski, K., Ruiz-Echevarria, M.J., Paushkin, S.V., Han, X., Weng, Y., Perlick, H.A., Dietz, H.C., Ter-Avanesyan, M.D., and Peltz, S.W. 1998. The surveillance complex interacts with the translation release factors to enhance termination and degrade aberrant mRNAs. Genes \& Dev. 12: 1665-1677.

Denning, G., Jamieson, L., Maquat, L.E., Thompson, E.A., and Fields, A.P. 2001. Cloning of a novel phosphatidylinositol kinase-related kinase: Characterization of the human SMG-1 RNA surveillance protein. J. Biol. Chem. 276: 22709-22714.

Fang, S. and Weissman, A.M. 2004. A field guide to ubiquitylation. Cell. Mol. Life Sci. 61: 1546-1561.

Fang, S., Lorick, K.L., Jensen, J.P., and Weissman, A.M. 2003. RING finger ubiquitin protein ligases: Implications for tumorigenesis, metastasis and for molecular targets in cancer. Semin. Cancer Biol. 13: $5-14$.

Gaba, A., Jacobson, A., and Sachs, M.S. 2005. Ribosome occupancy of the yeast CPA1 upstream open reading frame termination codon modulates nonsense-mediated mRNA decay. Mol. Cell 20: 449460.

Gehring, N.H., Kunz, J.B., Neu-Yilik, G., Breit, S., Viegas, M.H., Hentze, M.W., and Kulozik, A.E. 2005. Exon-junction complex components specify distinct routes of nonsense-mediated mRNA decay with differential cofactor requirements. Mol. Cell 20: $65-75$.

Goldstein, A.L. and McCusker, J.H. 1999. Three new dominant drug resistance cassettes for gene disruption in Saccharomyces cerevisiae. Yeast 15: 1541-1553.

Gonzalez, C.I., Ruiz-Echevarria, M.J., Vasudevan, S., Henry, M.F., and Peltz, S.W. 2000. The yeast hnRNP-like protein Hrp1/Nab4 marks a transcript for nonsense-mediated mRNA decay. Mol. Cell 5: 489-499.

Hatakeyama, S., Yada, M., Matsumoto, M., Ishida, N., and Nakayama, K.I. 2001. U box proteins as a new family of ubiquitin-protein ligases. J. Biol. Chem. 276: 33111-33120.

He, F. and Jacobson, A. 1995. Identification of a novel component of the nonsense-mediated mRNA decay pathway by use of an interacting protein screen. Genes \& Dev. 9: 437-454.

He, F., Brown, A.H., and Jacobson, A. 1996. Interaction between Nmd2p and Upflp is required for activity but not for dominantnegative inhibition of the nonsense-mediated mRNA decay pathway in yeast. RNA 2: 153-170.

He, F., Brown, A.H., and Jacobson, A. 1997. Upflp, Nmd2p, and Upf3p are interacting components of the yeast nonsense-mediated mRNA decay pathway. Mol. Cell. Biol. 17: 1580-1594.

Kadlec, J., Guilligay, D., Ravelli, R.B., and Cusack, S. 2006. Crystal structure of the UPF2-interacting domain of nonsense-mediated mRNA decay factor UPF1. RNA 12: 1817-1824.

Kashima, I., Yamashita, A., Izumi, N., Kataoka, N., Morishita, R., Hoshino, S., Ohno, M., Dreyfuss, G., and Ohno, S. 2006. Binding of a novel SMG-1-Upf1-eRF1-eRF3 complex (SURF) to the exon junction complex triggers Upf1 phosphorylation and nonsense-mediated mRNA decay. Genes \& Dev. 20: 355367.

Kobayashi, T., Funakoshi, Y., Hoshino, S., and Katada, T. 2004. The GTP-binding release factor eRF3 as a key mediator coupling translation termination to mRNA decay. J. Biol. Chem. 279: 45693-45700.

Lee, B.S. and Culbertson, M.R. 1995. Identification of an additional gene required for eukaryotic nonsense mRNA turnover. Proc. Natl. Acad. Sci. 92: 10354-10358.

Leeds, P., Peltz, S.W., Jacobson, A., and Culbertson, M.R. 1991. The product of the yeast UPF1 gene is required for rapid turnover of mRNAs containing a premature translational termination codon. Genes \& Dev. 5: 2303-2314.

Lykke-Andersen, J., Shu, M.D., and Steitz, J.A. 2000. Human Upf proteins target an mRNA for nonsense-mediated decay when bound downstream of a termination codon. Cell 103: 1121-1131.

Maderazo, A.B., He, F., Mangus, D.A., and Jacobson, A. 2000. Upf1p control of nonsense mRNA translation is regulated by Nmd2p and Upf3p. Mol. Cell. Biol. 20: 4591-4603.

Maderazo, A.B., Belk, J.P., He, F., and Jacobson, A. 2003. Nonsensecontaining mRNAs that accumulate in the absence of a functional nonsense-mediated mRNA decay pathway are destabilized rapidly upon its restitution. Mol. Cell. Biol. 23: 842-851.

Mendell, J.T., Medghalchi, S.M., Lake, R.G., Noensie, E.N., and Dietz, H.C. 2000. Novel Upf2p orthologues suggest a functional 
link between translation initiation and nonsense surveillance complexes. Mol. Cell. Biol. 20: 8944-8957.

Muhlrad, D., Decker, C.J., and Parker, R. 1994. Deadenylation of the unstable mRNA encoded by the yeast MFA2 gene leads to decapping followed by $5^{\prime} \rightarrow 3^{\prime}$ digestion of the transcript. Genes \& Dev. 8: 855-866.

Muhlrad, D., Decker, C.J., and Parker, R. 1995. Turnover mechanisms of the stable yeast PGK1 mRNA. Mol. Cell. Biol. 15: 2145-2156.

Ohnishi, T., Yamashita, A., Kashima, I., Schell, T., Anders, K.R., Grimson, A., Hachiya, T., Hentze, M.W., Anderson, P., and Ohno, S. 2003. Phosphorylation of hUPF1 induces formation of mRNA surveillance complexes containing hSMG-5 and hSMG7. Mol. Cell 12: 1187-1200.

Parker, R. and Sheth, U. 2007. P bodies and the control of mRNA translation and degradation. Mol. Cell 25: 635-646.

Peltz, S.W., Brown, A.H., and Jacobson, A. 1993. mRNA destabilization triggered by premature translational termination depends on at least three cis-acting sequence elements and one trans-acting factor. Genes \& Dev. 7: 1737-1754.

Perlick, H.A., Medghalchi, S.M., Spencer, F.A., Kendzior Jr., R.J., and Dietz, H.C. 1996. Mammalian orthologues of a yeast regulator of nonsense transcript stability. Proc. Natl. Acad. Sci. 93: 10928-10932.

Pulak, R. and Anderson, P. 1993. mRNA surveillance by the Caenorhabditis elegans smg genes. Genes \& Dev. 7: 1885-1897.

Serin, G., Gersappe, A., Black, J.D., Aronoff, R., and Maquat, L.E. 2001. Identification and characterization of human orthologues to Saccharomyces cerevisiae Upf2 protein and Upf3 protein (Caenorhabditis elegans SMG-4). Mol. Cell. Biol. 21: 209-223.

Sheth, U. and Parker, R. 2003. Decapping and decay of messenger RNA occur in cytoplasmic processing bodies. Science 300: 805808.

Sheth, U. and Parker, R. 2006. Targeting of aberrant mRNAs to cytoplasmic processing bodies. Cell 125: 1095-1109.
Shirley, R.L., Lelivelt, M.J., Schenkman, L.R., Dahlseid, J.N., and Culbertson, M.R. 1998. A factor required for nonsense-mediated mRNA decay in yeast is exported from the nucleus to the cytoplasm by a nuclear export signal sequence. J. Cell Sci. 111: 3129-3143.

Takahashi, S., Araki, Y., Sakuno, T., and Katada, T. 2003. Interaction between Ski7p and Upflp is required for nonsense-mediated 3'to-5' mRNA decay in yeast. EMBO J. 22: 3951-3959.

Wang, W., Czaplinski, K., Rao, Y., and Peltz, S.W. 2001. The role of Upf proteins in modulating the translation read-through of nonsense-containing transcripts. EMBO J. 20: 880-890.

Wang, W., Cajigas, I.J., García, E.J., Peltz, S.W., Wilkinson, M.F., and González, C.I. 2006. Role for Upf2p phosphorylation in Saccharomyces cerevisiae nonsense-mediated mRNA decay. Mol. Cell. Biol. 26: 3390-3400.

Weissman, A.M. 2001. Themes and variations on ubiquitylation. Nat. Rev. Mol. Cell Biol. 2: 169-178.

Weng, Y., Czaplinski, K., and Peltz, S.W. 1996a. Genetic and biochemical characterization of mutations in the ATPase and helicase regions of the Upf1 protein. Mol. Cell. Biol. 16: 5477-5490.

Weng, Y., Czaplinski, K., and Peltz, S.W. 1996b. Identification and characterization of mutations in the UPF1 gene that affect nonsense suppression and the formation of the Upf protein complex but not mRNA turnover. Mol. Cell. Biol. 16: 5491-5506.

Yamashita, A., Ohnishi, T., Kashima, I., Taya, Y., and Ohno, S. 2001. Human SMG-1, a novel phosphatidylinositol 3-kinase-related protein kinase, associates with components of the mRNA surveillance complex and is involved in the regulation of nonsensemediated mRNA decay. Genes \& Dev. 15: 2215-2228.

Zhang, S., Ruiz-Echevarria, M.J., Quan, Y., and Peltz, S.W. 1995. Identification and characterization of a sequence motif involved in nonsense-mediated mRNA decay. Mol. Cell. Biol. 15: 2231-2244. 

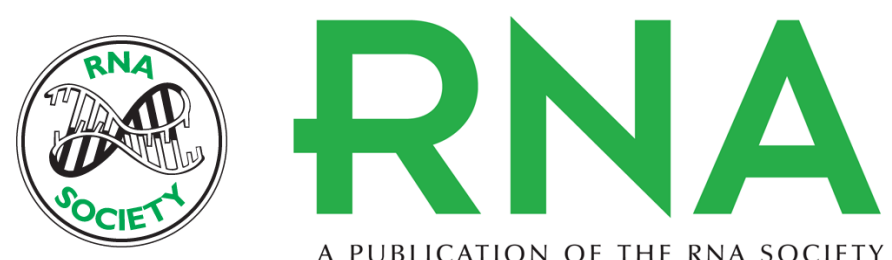

A PUBLICATION OF THE RNA SOCIETY

\section{Upf1 potentially serves as a RING-related E3 ubiquitin ligase via its association with Upf3 in yeast}

Shinya Takahashi, Yasuhiro Araki, Yuriko Ohya, et al.

RNA 2008 14: 1950-1958 originally published online August 1, 2008

Access the most recent version at doi:10.1261/rna.536308

$\begin{array}{ll}\text { References } & \begin{array}{l}\text { This article cites } 48 \text { articles, } 34 \text { of which can be accessed free at: } \\ \text { http://rnajournal.cshlp.org/content/14/9/1950.full.html\#ref-list-1 }\end{array}\end{array}$

License

Email Alerting Receive free email alerts when new articles cite this article - sign up in the box at the Service top right corner of the article or click here.

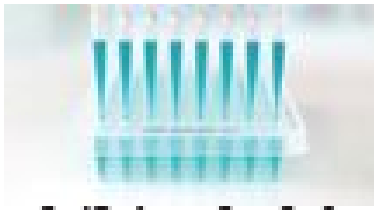

Providing Precise Solutions for your research.

To subscribe to RNA go to:

http://rnajournal.cshlp.org/subscriptions 